* Doutora em Direito (UFPE). Professora da Universidade de Pernambuco (UPE) e do Programa de Pós-Graduação em Direito (Mestrado) da Faculdade Damas. Advogada da União. E-mail: flavia-santiago@uol.com.br

**Bacharel em Direito pela Universidade de Pernambuco (UPE) E-mail: gabriellacaldasc@ gmail.com

\section{Diálogos entre Cortes: o Estado de Coisas InCONSTITUCIONAL Na COLÔMBIA E No BRASIL (ADPF 347/DF)}

Dialogues Between Courts: the UnCOnstitutional State of AfFairs in Colombia AND BrazIL (ADPF 347/ $\mathrm{DF})$

Flávia Danielle Santiago Lima* Gabriella Caldas Clementino**

Como citar: LIMA, Flávia Danielle Santiago; CLEMENTINO, Gabriella Caldas. Diálogos entre cortes: o estado de coisas inconstitucional na Colômbia e no Brasil (ADPF 347/DF). Revista do Direito Público, Londrina, v. 15, n. 1, p. 153-173, abr. 2020. DOI: $10.5433 / 24157-108104-1.2020 v 15 n 1 p$. 153. ISSN: $1980-$ $511 \mathrm{X}$

Resumo: Como os tribunais podem responder às omissões dos poderes majoritários na formulação e execução de políticas públicas? Partindo desta pergunta de pesquisa, o artigo aborda o Estado de Coisas Inconstitucional, instituto desenvolvido na Colômbia e incorporado pelo Supremo Tribunal Federal na ADPF n $347 / \mathrm{DF}$, amparado em considerações quanto ao diálogo entre cortes sul-americanas. A pesquisa adota o método indutivo, na análise das decisões proferidas pelos tribunais colombiano e brasileiro, para exposição dos pressupostos de incidência e limites impostos à aplicação da construção jurisprudencial. Discute-se, assim, a viabilidade de ativismo judicial legitimado pela proteção dos direitos fundamentais, à luz do princípio da separação dos poderes, pelos tribunais encarregados pela revisão judicial.

Palavras-chave: Estado de coisas inconstitucional. Diálogos entre cortes. Corte Constitucional da Colômbia. Supremo Tribunal Federal. ADPF no 347/DF.

Abstract: How can courts respond to the omissions by majority powers in the formulation and implementation of public policy? Based on this question, this paper addresses the State of Unconstitutional Affairs, an institute developed in Colombia and incorporated by the Federal Supreme Court in ADPF n³47/DF, based on the many dialogues between South American courts. This research adopts the inductive method, in the analysis of 
the many decisions rendered by Colombian and Brazilian courts, in order to expose the incidental assumptions and limits imposed on the application of jurisprudential construction. This study, therefore, discusses the feasibility of judicial activism legitimized by the protection of fundamental rights, in light of the principle of the separation of powers, by the courts responsible for judicial review.

Keywords: Unconstitutional State Of Affairs. Dialogues between courts. Constitutional Court of Colombia. Brazilian Supreme Court. ADPF $n^{\circ} 347 / D F$. 


\section{INTRODUÇÃO}

Os direitos e garantias fundamentais constituem os elementos materiais das democracias, positivados nas normas constitucionais, cuja concretização depende da estruturação de programas de ação governamental, coordenados no âmbito dos poderes legislativo e executivo, cuja implementação - via de regra - compete às agências administrativas.

Contudo, em virtude da inércia dos poderes majoritários em estabelecer medidas para suprir lacunas, decorrente do desinteresse político e da omissão prolongada das autoridades públicas, há situações em que resta caracterizada a violação massiva e generalizada destes direitos. A teoria jurídica se esmera na criação de instrumentos que possam articular ações para assegurar a efetividade destes direitos, com especial atenção aos controles quanto ao desempenho das funções pela Administração Pública, que possui o aparato burocrático para lidar com estas pautas. Mais recentemente, construções jurídicas como o Estado de Coisas Inconstitucional (ECI), criação da Corte Constitucional Colombiana, privilegiam a tomada de medidas específicas pelo próprio Poder Judiciário (YEPES, 2007).

Toma-se em conta, em tempos de "transconstitucionalismo" (NEVES, 2014), o estabelecimento de uma "comunidade global de cortes" (SLAUGHTER, 2013, p. 193-195), em que são reconhecidas as influências recíprocas entre tribunais ao redor do mundo, com constantes invocações ao direito transnacional, conceitos e teorias nas decisões locais, em uma troca de experiências (WALDRON, 2005, p. 129).

Neste particular, o engajamento em um diálogo (ou integração) com a Corte Constitucional da Colômbia, por parte do Supremo Tribunal Federal (STF), mostra uma nova faceta deste fenômeno: a aproximação entre ordens jurídicas sul-americanas, numa ruptura com a tradição de "quase total ausência de migração de ideias constitucionais na região", como já apontado por Virgílio Afonso da Silva (2010, p. 522).

Deste modo, o trabalho questiona, sob a luz de uma concepção democrática e organizacional da separação dos poderes, se "em caso de omissões dos poderes majoritários na execução de políticas públicas, cabe ao Poder Judiciário atuar como um garantidor dos direitos fundamentais sociais quando caraterizada uma tutela estatal deficiente?"

Para responder à pergunta de pesquisa, o objetivo geral é analisar a viabilidade da aplicação do ECI no Brasil, a partir da experiência colombiana, como forma de assegurar direitos pela via judicial, quando caracterizadas omissões estruturais dos outros poderes.

Inicialmente, propõe-se a abordagem do ECI no contexto constitucional colombiano, diante dos desafios para a construção deste instituto. Num segundo momento, expõe os caracteres de sua aplicação pelo STF, na Arguição de Descumprimento de Preceito Fundamental no 347/ DF, quando foi transplantado o ECI para a realidade brasileira, para tutelar os direitos dos presos diante das omissões dos poderes públicos. A recepção do instituto pelo STF foi objeto de profícuo 
debate entre os constitucionalistas brasileiros, sobretudo nas obras de Carlos Alexandre Campos, Dirley da Cunha e Lenio Streck, cujos argumentos oscilam em torno da viabilidade de intervenção judicial em situações semelhantes, a caracterizar ou não ativismo judicial por parte do Tribunal. Ao final questiona-se a aplicação do instituto pelo STF, na avaliação da ocorrência de um efetivo diálogo entre o Tribunal brasileiro e a Corte Colombiana.

O desenvolvimento da pesquisa parte de abordagem teórica, com o método indutivo, com o estudo de casos particulares por meio de análise exploratório-descritiva, para a organização das premissas em torno da construção do "estado de coisas inconstitucional" na jurisprudência da Corte Constitucional da Colômbia, e estabelecimento das proposições gerais do instituto, numa comparação com sua aplicação pelo STF. Para tal fim, utiliza-se primordialmente pesquisa documental (decisões judiciais) e bibliográfica, com literatura constitucional de ambos os países.

\section{ESTADO DE COISAS INCONSTITUCIONAL: UMA CRIAÇÃO DA CORTE CONSTITUCIONAL COLOMBIANA?}

O termo "Estado de Coisas Inconstitucional" foi utilizado pela primeira vez na Corte Constitucional da Colômbia, porém é certo que os elementos essenciais dessa técnica decisória já foram aplicados pelos poderes judiciários de outros sistemas jurídicos (BALDI, 2013, p. 54). Este modelo inspirou-se na controvérsia jurisprudencial ocorrida nos Estados Unidos da América, tendo raízes na teoria dos structural remedies, que defendiam a possibilidade de garantia da dimensão objetiva dos direitos fundamentais pelo Poder Judiciário, mesmo que isso implicasse intervenção em políticas públicas. Como julgado paradigmático, aponta-se o célebre caso Brown vs. Board of Education of Topeka, de 1955 (PEREIRA; GONÇALVES, 2015, p. 149), em que foi julgada a inconstitucionalidade da política de segregação racial nas escolas, marco na garantia das liberdades civis e amplamente referenciado como exemplo do potencial da revisão judicial para a proteção de minorias (BAUM, 2010, p. 23).

Ao analisar o referido caso, dois argumentos evidenciam que a Corte Warren, a despeito de não ter se valido da nomenclatura, aplicou técnica decisória equivalente ao Estado de Coisas Inconstitucional. Em primeiro lugar, constatou violação massiva e generalizada dos direitos apontados no caso, a atingir expressivo contingente de cidadãos estadunidenses, de sorte que a decisão deveria ser estendida a todos os afrodescendentes. Na mesma decisão, os Justices determinaram a realização de um conjunto de medidas concretas pelos órgãos e agentes públicos, com vistas à superação do estado de inconstitucionalidade.

Espelhando-se no modelo norte-americano, em 1997 a Corte Constitucional Colombiana declarou, pela primeira vez, o Estado de Coisas Inconstitucional (ECI), na Sentencia de Unificacion - SU 559/97, que questionava a perda de direitos sociais (previdência e saúde) garantidos aos professores da educação pública. A partir de então, o tribunal colombiano utiliza-se deste instrumento para "aproximar a realidade social concreta das promessas de direitos 'no papel' e acaba atuando como agente de transformação social" (CAMPOS, 2016, p. 98). 
Todavia, o recurso ao ECI não deve ser interpretado apenas como uma manifestação isolada de maior protagonismo da Corte Colombiana, mas num contexto de fortalecimento do Poder Judiciário entre os países latino-americanos na transição entre os anos 1980 e 1990, através de reformas ou estabelecimento de novas constituições, característico do cenário de transição à democracia (HIRSCHL, 2004, p. 6-12). Trata-se de uma resposta à histórica configuração institucional de hegemonia do executivo, legislativo frágil e afastado da sociedade e judiciário de pouca relevância, comum na região (BARROSO, 2015).

Em relação a outros países da América do Sul, a Corte Constitucional Colombiana é considerada paradigma do ativismo judicial. De acordo com Rodrigo Uprimny Yepes (2007), dentre outros fatores, a transferência ao Poder Judiciário de decisões típicas da arena política seria consequência da incredulidade popular quanto aos agentes políticos eleitos, diante da massiva corrupção vivenciada pelo país. E nesse contexto foi promulgada a Constituição da Colômbia em 1991, que instituiu a Corte Constitucional, garantindo-lhe significativas competências e poderes de controle sobre os atos governamentais. Nos termos do art. 241 da Constituição Colombiana, a Corte tem função de garantir a supremacia e a integridade do seu texto. Para tal fim, exerce um controle misto de controle de constitucionalidade (difuso e concentrado), de forma repressiva ou preventiva, de sorte que possui um monopólio relativo da revisão judicial de legislação, eis que ela pode ser exercida por todos os membros do Poder Judiciário (LOSING, 2002, p. 284). Assegurado, ainda, amplo acesso à sua jurisdição. Desde então, a Corte exerce papel incisivo na promoção dos direitos fundamentais e controle das práticas dos poderes (CAMPOS, 2016, p. 100).

Fortalecida institucionalmente, popular e ativista no controle das decisões políticas relevantes do Executivo e do Legislativo, o intervencionismo da Corte Colombiana consubstanciava uma práxis casuística, desprovida de contornos concretos. Outrossim, as expressões jurisprudenciais anteriores respaldam o comportamento da Corte quando declara e estabelece o ECI, afirmando para si mesma a legitimidade para interferir no processo de implementação das políticas públicas devido aos quadros de violação de direitos fundamentais decorrentes de falhas estruturais do Estado (VILLALOBOS; MACHADO, 2014, p. 69-77).

As bases teóricas do ECI e sua efetividade como um instrumento capaz de minimizar as violações aos direitos fundamentais foram estabelecidas em três julgados mais proeminentes sobre a temática. A Sentencia de Unificacion - 559/1997 teve como principal consequência a extensão dos efeitos de decisões que englobassem um número indeterminado de pessoas. A Sentencia de Tutela - 153/1998 explorou eventuais falhas na implementação do ECI. Por fim, a Sentencia de Tutela - 025/2004 é uma das mais importantes decisões da Corte Colombiana, pois trouxe a definição dos pressupostos necessários para o reconhecimento deste instituto. Dessa forma, passase a analisar detalhadamente cada uma delas.

\subsection{Extensão Coletiva dos Efeitos da Coisa Julgada: a Sentencia de Unificacion (SU) 559/1997}

$\mathrm{Na}$ sentença precursora, quarenta e cinco professores dos municípios de María La Baja 
e Zambrano alegavam descumprimento de seus direitos previdenciários. A Corte Colombiana passou a analisar, em sede de recurso, acumuladas ações de tutela propostas por esses docentes, que alegavam violação do direito fundamental à saúde por parte dos prefeitos locais, pois contribuíam para o fundo previdenciário denominado Fundo de Prestación Social, mas não recebiam a contrapartida de direitos sociais básicos (COLÔMBIA, 1997).

Ao analisar o caso, a Corte verificou que a política dos subsídios educacionais possuía uma estrutura desigual, levando algumas entidades territoriais destituídas de recursos ao descumprimento das normas previdenciárias, diante da distorção distributiva verificada no governo central. Os juízes constitucionais observaram que referida situação não se restringia aos docentes que ingressaram com a demanda. Constatada, ainda, a omissão de diversos órgãos e agentes na concretização dos comandos constitucionais.

Concluiu-se que a multiplicação de processos e a reiteração da jurisprudência não seriam suficientes para solucionar possíveis demandas que poderiam surgir, visto que havia descumprimento dos direitos fundamentais de um número amplo e indeterminado de pessoas.

Desta forma, a Corte Constitucional entendeu por criar um instrumento jurisprudencial que implicasse na extensão coletiva dos efeitos da coisa julgada. A partir desse ponto, a Corte: (1) declarou o ECI; (2) determinou que os municípios que se encontrassem em situação similar corrigissem a inconstitucionalidade em prazo razoável; (3) ordenou o envio de cópias da sentença aos Ministros da Educação e da Fazenda e do Crédito Público, ao Diretor do Departamento Nacional de Planejamento, aos membros do CONPES social, aos Governadores e Assembleias, aos Prefeitos e aos Conselhos Municipais, para a tomada de providências (CAMPOS, 2016, p. $122)$.

Diante disso, além de garantir os direitos subjetivos dos litigantes, a Corte deliberou pela proteção da dimensão objetiva dos direitos fundamentais postos em jogo. Essa dimensão objetiva da sentença, voltada a superar o ECI a partir da identificação de contexto amplo e estrutural de causas e efeitos, é evidenciada nesta passagem:

O Tribunal Constitucional tem o dever de colaborar harmoniosamente com os outros órgãos do Estado para a realização dos seus propósitos. O fato de que o estado de coisas não só serve como o suporte causal do prejuízo fundamental examinado, mas também, em relação a situações semelhantes, não pode restringir o alcance do requisito formulado ${ }^{1}$ (COLÔMBIA, 1997, tradução nossa).

Com a prolatação do julgado, passou-se a admitir a extensão dos efeitos de decisões que interessassem a um número indeterminado de pessoas àqueles que dela pudessem se beneficiar; ou seja, garantiu-se efeito erga omnes às decisões judiciais.

Germán Santiago Montenegro (2015, p. 23, tradução nossa), também aponta outras

1 La Corte Constitucional tiene el deber de colaborar de manera armónica con los restantes órganos del Estado para la realización de sus fines. [...]La circunstancia de que el estado de cosas no solamente sirva de soporte causal de la lesión iusfundamental examinada, sino que, además, lo sea en relación con situaciones semejantes, no puede restringir el alcance del requerimiento que se formule. 
características que tornam a referida sentencia de vital importância para o ECI:

Neste julgamento, o tribunal toma como apoio legal o art. 113 da Constituição Política Colombiana onde ordena a atividade harmônica dos ramos do poder público, pelo qual o Tribunal é obrigado a notificar as autoridades públicas da existência de certos fatos que atacam a Constituição. [...] outro elemento de grande importância em que o Tribunal fundamentou para a implementação desta figura e serve como um pilar para o seu apoio é o "princípio da progressividade" C. Const., em diferentes julgamentos, invocou argumentar o requisito de cumprimento efetivo dos direitos fundamentais. ${ }^{2}$

\subsection{A Sentencia de Tutela (T) 153/1998: da Necessidade de um Sistema de Monitoramento das Medidas Estruturantes}

O segundo caso emblemático de declaração do Estado de Coisas Inconstitucional abordou o quadro de superlotação das penitenciárias colombianas, tema semelhante ao posteriormente versado na ADPF no 347/DF, quando o STF brasileiro tratou do instituto. Segundo a magistrada Clara Inés Vargas Hernández (2003) é “uno de los fallos más importantes proferidos por la Corte Constitucional colombiana".

A superlotação dos presídios de Bogotá e de Bellavista de Medellín ensejou a propositura da ação originária do feito, tendo a Corte Constitucional observado que as precárias condições dos dois presídios se repetiam na maior parte dos estabelecimentos prisionais do país. Os juízes constataram que todos os elementos ensejadores para a declaração do ECI estavam presentes e que o sistema prisional não estava servindo para a ressocialização dos presos (COLÔMBIA, 1998).

A "tragédia diária dos cárceres" foi tida como um produto da omissão permanente do Estado e da sociedade, com destaque para a ausência de provimentos legislativos destinados à melhoria das condições penitenciárias e para a inexistência de políticas públicas voltadas a este fim. Ao considerar que a questão não seria apenas de ordem pública, mas um grave problema social, outra alternativa não vislumbrou a Corte que não a prolação de uma sentença estrutural, porquanto presentes os pressupostos de incidência desta técnica decisória.

Para findar o caso, os juízes constitucionais decidiram por elaborar um plano nacional de reparação e construção dos presídios por parte do governo. Também determinaram a movimentação de recursos para que fossem executados projetos e criadas unidades carcerárias nas entidades territoriais. Por fim, encaminharam medidas a serem adotadas pelo Presidente da República, com a finalidade de encerrar as violações massivas à dignidade e à integridade física dos apenados.

Contudo, apesar das inúmeras ordens dirigidas a várias instituições para solução do problema geral da superlotação carcerária, a decisão não se revelou útil. A Corte teria se equivocado

2 En esta sentencia la corte toma como sustento jurídico el Art 113 de la Constitucional Politica Colombiana donde ordena la actividad armónica de las ramas del poder público, por lo que la Corte está en la obligación de notificar a las autoridades públicas la existencia de ciertos hechos que agreden la Constitución. [...] otro elemento de gran importancia en el cual la Corte se fundamentó para la implementación de esta figura y sirve como pilar para su sustentación es el "principio de progresividad" La C. Const., en distintas sentencias, lo ha invocado para argumentar la exigencia del cumplimiento efectivo de los derechos fundamentales. 
ao proferir ordens estruturais sem estabelecer procedimentos adequados de monitoramento durante a fase de implementação. Para Libardo José Ariza (2013, p. 132-133, tradução nossa), "a decisão faz contribuições substanciais para a proteção dos direitos, mas tem um impacto mínimo sobre a situação abordada [...] isso se deve principalmente à ausência de sistemas de monitoramento para verificar a implementação da decisão"3.

Logo, a grande contribuição desse caso foi a constatação da ineficácia de sentenças estruturais e, portanto, dos pronunciamentos jurisdicionais, sem um sistema institucional de controle de seu cumprimento. Por isso, nas suas últimas decisões, a Corte vem determinando que a Defensoria del Pueblo crie um grupo de monitoramento do cumprimento das ordens estruturais, devendo informar o andamento das medidas estabelecidas (CARVALHO; OLIVEIRA; SANTOS, 2017, p. 312).

\subsection{A Conformação do ECI na Sentencia de Tutela (T) 025/2004: Cautela na Fixação dos Pressupostos e Cuidados na Fiscalização da Implementação}

A Sentença de Tutela $(\mathrm{T})$ - 025/2004 é considerada o julgado mais relevante proferido pela Corte Constitucional colombiana referente à construção do Estado de Coisas Inconstitucional. A decisão teve origem em 108 ações de tutela propostas por 1.150 famílias refugiadas, “desplazadas”, em razão da guerra do narcotráfico, especialmente pela atuação das FARC (Forças Armadas Revolucionárias da Colômbia). A situação reclamava a adoção de providências por parte dos diversos órgãos e agentes políticos no sentido de se estabelecer uma política nacional de acomodação e atendimento às famílias deslocadas, pondo fim às graves e persistentes violações aos direitos fundamentais de seus membros (GARAVITO; FRANCO, 2010, p. 79).

O grande diferencial deste caso deu-se porque a Corte reteve jurisdição sobre o litígio para assegurar a implementação total de suas ordens. Assim, além de determinar as políticas públicas dirigidas à tutela de direitos em jogo, também supervisionou o cumprimento da decisão, realizou audiências públicas para debater as soluções formuladas e proferiu novas decisões e ordens. Não obstante, dispensou a atuação de advogados, de modo a facilitar a interposição dos recursos, admitindo que estes fossem elaborados diretamente pelas pessoas prejudicadas (CAMPOS, 2016, p. 142-ss).

A Corte teve a cautela de não exercer diretamente as competências dos outros poderes, mas exigiu que estes tomassem providências para assegurar os direitos das pessoas deslocadas (COLÔMBIA, 2004). E, mais uma vez, prezou pela proteção da dimensão objetiva dos direitos fundamentais envolvidos.

Ao examinar a ordem jurídica colombiana e a atuação dos poderes constituídos no tocante à matéria, a Corte observou que o debate político nacional se mostrava alheio às precárias condições existenciais dos refugiados, assim como inexistiam programas governamentais operantes

3 Among those who focus on the implementation phase of USoA rulings it is agreed that the ruling makes substantial contributions to the protection of rights but has a minimal impact on the state of affairs it sought to address. This is due principally to the absence of monitoring systems to verify the ruling's implementation. 
direcionados à sua assistência.

O julgado identificou que a violação massiva dos direitos fundamentais das pessoas deslocadas não era consequência apenas da ineficácia das políticas públicas, mas também da inaplicabilidade da matéria legislativa nesse campo - o que configurava omissão legislativa inconstitucional, como expõe Carlos Alexandre $\mathrm{Campos}^{4}$. A soma desses problemas demonstra a existência de falhas estruturais.

As alegações dos demandantes eram de que o Estado não cumpriu sua obrigação de proteger a população deslocada e responder efetivamente aos seus pedidos. Como ficou claro com os fatos do acórdão, quando as vítimas do deslocamento solicitaram a assistência a que tinham direito nos termos da Lei 387 de 1997, receberam em resposta todos os tipos de desculpas por parte das autoridades ${ }^{5}$ (GARAVITO; FRANCO, 2010, p. 81, tradução nossa).

Por essa razão, os juízes colombianos concluíram que estavam presentes os elementos caracterizadores do ECI, dissertando, para tanto, sobre os pressupostos teóricos de incidência para decretação do instituto, assim explicitados na sentença:

\begin{abstract}
Dentre os fatores valorados pela Corte para definir se existe um estado de coisas inconstitucional, cabe destacar os seguintes: (i) a violação massiva e generalizada de vários direitos constitucionais que afeta um número significativo de pessoas; (ii) a omissão prolongada das autoridades no cumprimento de suas obrigações para garantir tais direitos; (iii) a adoção de práticas inconstitucionais, como a incorporação da via judicial como parte do procedimento para garantir o direito violado; (iv) a não expedição de medidas legislativas, administrativas ou orçamentárias necessárias para evitar a violação dos direitos; (v) a existência de um problema social cuja solução reclama a intervenção de vários órgãos e agentes públicos, requer a adoção de um conjunto complexo e coordenado de ações e exige um nível de recursos que demanda um esforço orçamentário adicional relevante; (vi) se todas as pessoas afetadas pelo mesmo problema recorressem à justiça para obter a proteção de seus direitos, isso produziria um abarrotamento de processos no Poder Judiciário ${ }^{6}$ (COLÔMBIA, 2004, tradução nossa).
\end{abstract}

4 Para o autor, a omissão normativa inconstitucional não é decorrente somente da inércia ou atuação falha do legislativo, não se restringindo as normas de eficácia limitada, mas também de órgãos administrativos e até mesmo esta omissão pode-se dar pela atuação descoordenada dos poderes públicos (CAMPOS, 2016, p. 55-94).

$5 \mathrm{La}$ raíz de los reclamos de los demandantes era el incumplimiento del Estado de su deber de protección a la población desplazada y respuestas efectivas a sus solicitudes. Como quedó claro em los hechos de la sentencia, cuando las víctimas del desplazamiento solicitaban la ayuda a la que tenían derecho em virtude de la Ley 387 de 1997, recibían como respuesta todo tipo de excusas por parte de las autoridades.

6 Dentro de los factores valorados por la Corte para definir si existe un estado de cosas inconstitucional, cabe destacar los siguientes: (i) la vulneración masiva y generalizada de varios derechos constitucionales que afecta a un número significativo de personas; (ii) la prolongada omisión de las autoridades en el cumplimiento de sus obligaciones para garantizar los derechos; (iii) la adopción de prácticas inconstitucionales, como la incorporación de la acción de tutela como parte del procedimiento para garantizar el derecho conculcado; (iv) la no expedición de medidas legislativas, administrativas o presupuestales necesarias para evitar la vulneración de los derechos. (v) la existencia de un problema social cuya solución compromete la intervención de varias entidades, requiere la adopción de un conjunto complejo y coordinado de acciones y exige un nivel de recursos que demanda un esfuerzo presupuestal adicional importante; (vi) si todas las personas afectadas por el mismo problema acudieran a la acción de tutela para obtener la protección de sus derechos, se produciría una mayor congestión judicial. 
Pode-se afirmar que a Sentencia T-025/2004 é a mais completa, por sistematizar e unificar os critérios para a incidência do ECI e, ainda, ao estabelecer o mais complexo conjunto de ordens dirigidas ao poder público, para assegurar a superação da situação declarada. Além disso, a Corte colombiana implementou a prática do monitoramento, ausente na sentença relativa ao sistema carcerário, o que culminou em seu fracasso, mostrando preocupação com a efetividade de sua decisão.

Esse momento agregou efetividade ao ECI em casos verdadeiramente dramáticos. Ainda que não se possa falar em uma "doutrina acabada", a Sentencia T-025/2004, na sua formulação e execução, revela um estágio bastante avançado de uma prática a ser descrita e testada criticamente pelo que se pode entender como sendo uma "doutrina do ECI" (CAMPOS, 2016, p. 166).

É possível perceber que em suas últimas decisões a Corte Constitucional da Colômbia adotou a prática do monitoramento para superar as falhas antes cometidas no tocante ao sistema penitenciário. Nas recentes Sentencia T-388/2013 e Sentencia T-762/2015, a Corte voltou a declarar o Estado de Coisas Inconstitucional do sistema carcerário e, como já exposto, determinou que a Defensoría del Pueblo criasse um grupo de monitoramento do cumprimento das novas ordens estruturais.

\section{DA CONSTRUÇÃO JURISPRUDENCIAL AO INSTITUTO JURÍDICO: REQUISITOS PARA APLICAÇÃO DO ESTADO DE COISAS INCONSTITUCIONAL}

A priori, cumpre reforçar que o principal aspecto do ECI é a intervenção do judiciário no ciclo das políticas públicas, ou seja, quando a Corte declara sua existência, afirma para si a legitimidade para interferir na forma, na implementação e na agenda das políticas públicas, quando há uma violação massiva e sistemática de direitos fundamentais.

O ECI está presente não apenas quando há o descumprimento de enunciados constitucionais específicos, mas quando constatadas falhas estruturais decorrentes da deficiência institucional e estrutural do Estado. Isto é, está-se diante de um quadro real, atual e objetivo de tutela estatal deficiente de direitos fundamentais e sociais, no qual esses direitos não estão sendo efetivados. São situações nas quais, a despeito de leis que resguardem direitos, não há estrutura apta a tornar realidade os comandos normativos.

Para Samuel de Jesus Vieira (2016), o Estado de Coisas Inconstitucional presta-se a criar "soluções estruturais ao Estado para extirpar situações de inconstitucionalidade que violem, grave e continuamente, os princípios fundamentais [...] frente às populações mais vulneráveis, em face das falhas ou omissões do poder público em cumprir suas disposições"”.

7 Já Carlos Alexandre Campos (2016, p. 187) define o ECI como “A técnica de decisão por meio da qual cortes e juízes constitucionais, quando rigorosamente identificam um quadro de violação massiva e sistemática de direitos fundamentais decorrente de falhas estruturais do Estado, declaram a absoluta contradição entre os comandos normativos constitucionais e a realidade social, e expedem ordens estruturais dirigidas a instar um amplo conjunto de órgãos e autoridades a formularem e a implementarem políticas públicas voltadas à superação dessa realidade 
A Corte Colombiana na Sentencia T-025/2004, como demonstrado no tópico anterior, agrupou elementos definidos em outras decisões e determinou que seriam seis os fatores necessários para declarar a vigência de um Estado de Coisas Inconstitucional. A partir destes elementos da construção jurisprudencial, a doutrina colombiana identifica condições para a aplicação do instituto:

Estes seis elementos podem ser resumidos em dois fatores principais denominados pelo Dr. Cesar Rodríguez Garavito, como condições de processo (falhas estruturais de políticas públicas no país) e condições de resultado (violação massiva e sistematizada de direitos fundamentais de um número indeterminado de pessoas). E um terceiro fator seria a necessidade primordial do trabalho conjunto de várias autoridades públicas com a finalidade de uma realidade contrária à Constituição (QUINTERO LYONS; NAVARRO MONTERROZA; IRINA MEZA, 2011, p. 73 , tradução nossa). ${ }^{8}$

A necessidade de identificação destes pressupostos é condição essencial para o uso do ECI, de modo a evitar decisões arbitrarias e ilegítimas. Assim, será reconhecido o ECI para a superação de violações de direitos fundamentais, exigindo-se a implementação de ordens dirigidas a uma pluralidade de órgãos, de modo que todos sejam responsáveis pela solução da questão. É possível atentar para a conexão entre ECI e sentenças estruturais, caracterizada pelo alcance a número amplo de pessoas, várias entidades e por implicar ordens de execução complexa.

O alcance estrutural do ECI está vinculado à fixação de structural remedies, pela qual os juízes devem interferir nas escolhas orçamentárias e nos ciclos de formulação, implementação e avaliação de políticas públicas, lançando mão de ordens que, ao mesmo tempo, redimensionem esses ciclos e permitam melhor coordenação estrutural.

Assim, é inegável que o reconhecimento do Estado de Coisas Inconstitucional pressupõe uma atuação ativista do Tribunal (uma espécie de ativismo judicial estrutural), na medida em que as decisões judiciais vão induvidosamente interferir nas funções executivas e legislativas, com repercussões, sobretudo, orçamentárias (CUNHA JUNIOR, 2015).

A legitimidade do ativismo empregado no ECI se dá na apreciação de cada caso concreto, na qual se analisa a conformidade do exercício do poder judiciário aos limites institucionais impostos pela constituição. Assim, o ativismo estrutural, utilizado nas decisões do ECI, ocorre nas oportunidades em que juízes atuam diante da inércia dos outros poderes, pois entende-se que todas as decisões e omissões estatais sujeitam-se ao controle de legitimidade constitucional.

Sendo assim, o Estado de Coisas Inconstitucional é resultado de situações concretas de paralisia parlamentar ou administrativa sobre determinadas matérias. Há nesses casos falhas estruturais e omissões legislativas e administrativas e, por isso, surge necessidade da atuação ativista das cortes como um meio, ainda que longe do ideal em uma democracia, para superar inconstitucional".

8 Estos seis elementos, pueden ser resumidos en dos factores principales que son denominados por el doctor Cesar Rodríguez Garavito, como condiciones de proceso (fallas estructurales de las políticas públicas en el país) y condiciones de resultado (violación masiva y sistematizada de los derechos fundamentales de un número indeterminado de personas). Y un tercer factor sería la necesidad imperiosa del trabajo en conjunto de diversas autoridades públicas para la modificación 6 de una realidad que resulta contraria a la Constitución. 
os desacordos políticos e institucionais, a falta de coordenação entre órgãos públicos, temores de custos políticos, legislative blindspots ${ }^{9}$, sub-representação de grupos sociais minoritários ou marginalizados (CAMPOS, 2015).

\section{RUMO A UM DIÁlOGO ENTRE CORTES NA AMÉRICA DO SUL? A APLICAÇÃO DO ESTADO DE COISAS INCONSTITUCIONAL PELO STF NA ADPF 347/DF}

No ordenamento jurídico brasileiro, a partir do arranjo institucional e dispositivos materiais da Constituição Federal de 1988, há diversos mecanismos que legitimam a intervenção judicial e permitem ao Supremo Tribunal Federal influenciar no ciclo de políticas públicas. O fortalecimento das instituições judiciais, sobretudo do STF, é objeto de relativo consenso entre juristas e cientistas políticos ${ }^{10}$. Neste sentido, os meios processuais para a implementação do ECI pelo Tribunal estão presentes, de sorte que as dúvidas se referem aos mecanismos da separação de poderes, como se verá mais adiante.

A Arguição de Descumprimento de Preceito Fundamental (ADPF) é, hoje, o principal mecanismo para concretizar o ECI na realidade brasileira. Prevê a Lei 9.882/99 em seu art. $1^{\circ}$ que: “a arguição prevista no $\S 1^{\circ}$ do art. 102 da Constituição Federal será proposta perante o Supremo Tribunal Federal, e terá por objeto evitar ou reparar lesão a preceito fundamental, resultante de ato do Poder Público" (BRASIL, 1999).

Através desse dispositivo, percebe-se que a ADPF possui os requisitos necessários para a implantação do ECI, pois sob o conceito de "ato do Poder Público", pode-se encaixar perfeitamente a noção de falha estrutural. Enquanto o termo "lesão a preceito fundamental" satisfaz adequadamente a necessidade de que haja uma violação reiterada de direitos para configuração do instituto.

A figura do Estado de Coisas Inconstitucional, responsável por legitimar uma atuação mais incisiva do Poder Judiciário na implementação de políticas públicas e na alocação de recursos orçamentários, passou a ser debatida e ganhou relevo com o julgamento, no STF, do RE $\mathrm{n}^{\circ} 592.581$ (BRASIL, 2015c) e da ADPF $n^{\circ} 347$ (BRASIL, 2015a). Nessa oportunidade, foi decidido pelo Plenário do Tribunal, no dia 13 de agosto de 2015, que o Poder Judiciário poderia determinar que a Administração Pública realizasse reformas e obras emergenciais nos presídios, com o objetivo de garantir os direitos fundamentais dos encarcerados, nos seguintes parâmetros:

É lícito ao Judiciário impor à Administração Pública obrigação de fazer, consistente na promoção de medidas ou na execução de obras emergenciais em estabelecimentos prisionais para dar efetividade ao postulado da dignidade da pessoa humana e assegurar aos detentos o respeito à sua integridade física $\mathrm{e}$ moral, nos termos do que preceitua o art. $5^{\circ}$, XLIX, da Constituição Federal, não

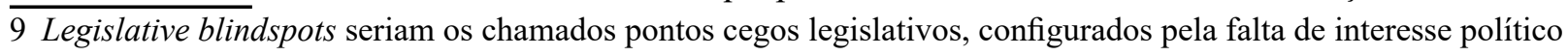
dos poderes representativos em tutelar os direitos de uma minoria.

10 Oscar Vilhena Vieira (2008) afirma que o STF seria "responsável por emitir a última palavra sobre inúmeras questões de natureza substantiva, ora validando e legitimando uma decisão dos órgãos representativos, outras vezes substituindo as escolhas majoritárias, até pelo reconhecimento doutrinário de temas judicializáveis". O autor salienta, especialmente, a ausência de constrangimentos do Tribunal para julgar as mais diversas questões. 
sendo oponível à decisão o argumento da reserva do possível nem o princípio da separação dos poderes (BRASIL, 2015c, p. 72, grifo nosso).

De acordo com a decisão, é clara a tentativa do STF de resguardar os direitos e princípios constitucionais tutelados, ao passo que afastou os princípios da separação dos Poderes e da reserva do possível, quando impôs ao Poder Executivo a obrigação de dar efetividade ao princípio constitucional da dignidade da pessoa humana e assegurar aos detentos o respeito à sua integridade física e moral (BRASIL, 2015c, p. 3).

Nesse contexto, a posição do Tribunal no RE $n^{0} 592.581$ foi reforçada no julgamento da Medida Cautelar na ADPF no 347, em 8 de setembro de 2015, ajuizada pelo Partido Socialismo e Liberdade (PSOL). Nessa medida, a organização partidária arguiu pelo reconhecimento da violação generalizada dos direitos fundamentais dos presos, além de solicitar que fossem determinadas medidas para implementação de providências no sistema carcerário do País. Ainda, o partido pugnou que fosse reconhecido, expressamente, o ECI relativo ao sistema penitenciário brasileiro, legitimando, portanto, atuação enfática do Poder Judiciário.

Também, a ADPF nº 347 (BRASIL, 2015a) sustenta que a situação calamitosa dos presídios nacionais viola o princípio da dignidade da pessoa humana (art. $1^{\circ}$, inc. III, da CRFB/1988), bem como uma vasta gama de direitos e garantias fundamentais, quais sejam: a vedação de tortura e tratamento desumano ou degradante (art. $5^{\circ}$, inc. III), a proibição de penas cruéis (art. $5^{\circ}$, inc. XLVII, alínea “e”), a garantia de respeito à integridade física e moral do preso (art. $5^{\circ}$, inc. XLIX), o direito de acesso à justiça (art. $5^{\circ}$, inc. XXXV), o devido processo legal (art. $5^{\circ}$, inc. LIV e LV), a presunção de inocência (art. $5^{\circ}$, inc. LVII) e os direitos sociais à saúde, educação, trabalho e segurança $\left(\operatorname{art.} 6^{\circ}\right)$.

Foi demonstrado na petição inicial que o número atual de presos no Brasil ultrapassava as 560.000 pessoas, ao passo que há 350.000 vagas existentes, estatística que corrobora a realidade de superlotação dos presídios brasileiros. Além disso, muitos desses detentos estavam sob custódia provisória. Estimou-se que $41 \%$ dos presos brasileiros eram provisórios, não possuindo contra si sentença penal condenatória. ${ }^{11}$

O Conselho Nacional de Justiça (CNJ, 2014), ao fazer inspeções em vários presídios, observou a existência de celas superlotadas, com detentos amontoados, sem camas ou colchões. Outra pesquisa referenciada na exordial, empreendida pelo Conselho Nacional do Ministério Público (CNMP), verificou que, entre 1.589 estabelecimentos prisionais visitados, 780 não possuíam camas e 365 não ofereciam colchões para todos os detentos. A esses fatos, somam-se a ausência da separação entre presos definitivos e provisórios, a inexistência de assistência jurídica aos reclusos e de prestação de serviços de saúde e de alimentação adequada.

Dado o quadro caótico do sistema carcerário brasileiro, o Partido Socialismo e Liberdade requereu o deferimento de um conjunto de medidas cautelares para minimizar a violação atual, como o objetivo de evitar prisões demasiadas a partir da realização de audiências de custódias, da 
motivação expressa das razões que impossibilitam a aplicação das medidas cautelares alternativas à privação de liberdade, de mutirões carcerários e do imediato descontingenciamento das verbas existentes no Fundo Penitenciário Nacional - FUNPEN, além de outras arguições.

A medida cautelar foi deferida parcialmente, para determinar que os juízes e os tribunais realizassem, em até 90 dias, audiências de custódia, viabilizando o comparecimento do preso perante a autoridade judiciária no prazo máximo de 24 horas e à União que liberasse o saldo acumulado do Fundo Penitenciário Nacional para a finalidade para a qual foi criado. Porém, a maioria indeferiu as medidas quanto aos pedidos de interpretação da lei processual penal para restringir a aplicação de prisões preventivas, medida considerada necessária para acabar com o problema da superlotação.

O ECI foi declarado expressamente pela maioria dos ministros, assim como atestada a sua vigência. O Ministro Relator apontou a violação reiterada dos direitos fundamentais dos presos, as falhas estruturais e a falência das políticas públicas, bem como reconheceu a necessidade do Tribunal tomar medidas estruturais, sendo estes os pressupostos necessários para o seu reconhecimento. ${ }^{12}$

Dessa forma, a atuação da jurisdição constitucional na promoção da democracia é legítima, não como o único, mas como um dos caminhos possíveis em direção a uma real e efetiva democracia, conforme pode ser observado no julgamento.

\section{ENTRE EFETIVIDADE DE DIREITOS FUNDAMENTAIS E ATIVISMO JUDICIAL: O DILEMA BRASILEIRO}

O caso acima retratado traz uma semelhança com o caso colombiano estudado na Sentencia de Tutela $(T)$ - 153/1998, no qual existiam problemas de superlotação carcerária, condições precárias de higiene, entres outros, que implicavam tratamento desumano. Deve-se ressaltar que as graves deficiências e violações de direitos, presentes em todas as unidades da Federação brasileira, são de responsabilidade dos três poderes. Portanto, há um quadro massivo de violação de diferentes direitos fundamentais, o que evidencia o caráter estrutural de omissões estatais. Assim, sendo possível constatar problemas de agenda política, de formulação e de implementação de políticas públicas, como também de aplicação da lei penal.

Para Carlos Alexandre Campos (2016, p. 271-276) não há dúvidas que os presídios brasileiros violam os direitos fundamentais dos presos. De acordo com o autor, "o sistema carcerário brasileiro é um ECI". Nesse caso, vislumbra-se a possibilidade de que o Tribunal atue em decisões primariamente políticas sem que se possa cogitar afronta ao princípio constitucional da separação de poderes. A intervenção judicial mostra-se aceitável, presente o padrão elevado de omissão estatal frente à situação de violação generalizada de direitos fundamentais. Além disso o Tribunal não chega a elaborar políticas públicas, mas coordena-las.

Entretanto, durante o julgamento da medida cautelar, em Plenário, foram expostas algumas divergências em relação à incorporação do instituto em análise.

12 Tais informações podem ser extraídas do Site de Noticiais do Supremo Tribunal Federal (BRASIL, 2015b). 
Ao se manifestar, o Advogado-Geral da União reconheceu a falta de capacidade de execução dos projetos pelos Estados e má aplicação das diretrizes normativas por esses, mas asseverou que tais problemas não decorrem da falta de recursos. Aduziu o Ministro que a solução para a crise dos presídios brasileiros estava sendo gestada por todos poderes, mas faltaria diálogo entre eles. Já a Vice-Procuradora-Geral da República expôs que as medidas cautelares requeridas seriam "abrangentes e generalizadas." 13

A doutrina jurídica acompanha as críticas à implementação do Estado de Coisas Inconstitucional no Brasil, por suas consequências para o próprio arranjo constitucional. De acordo com De Giorgi, Faria e Campilongo (2015), “se assim estão as ‘coisas' - e, por isso, a ordem jurídica é ineficaz e o acesso à Justiça não se concretiza -, por que não decretar a inconstitucionalidade da Constituição e determinar o fechamento dos tribunais?"

Para Lênio Luis Streck (2015), um Estado Social não pode ser construído por decisões judicias, tampouco cabe ao Poder Judiciário a implementação de políticas públicas, embora reconheça a importância da instituição para a efetivação da Constituição:

O que quero dizer é que, em sendo factível/correta a tese do ECI, a palavra "estruturante" poderá ser um guarda-chuva debaixo do qual será colocado tudo o que o ativismo querer, desde os presídios ao salário mínimo. Mas, qual será a estrutura a ser inconstitucionalizada? Sabemos que, em uma democracia, quem faz escolhas é o Executivo, eleito para fazer políticas públicas. Judiciário não escolhe [...]. Não necessitamos de uma análise consequencialista para entender o problema dos efeitos colaterais de uma decisão da Suprema Corte (STRECK, 2015).

Dessa forma, Streck (2015) aduz que o ECI é uma evidente ameaça à separação dos poderes, pois o instituto permite a invocação de razões extrajurídicas para que o Poder Judiciário opere, além de pontuar a desnecessidade de "lançar mão desse 'argumento de teoria colombiana' para tratar do que a legislação processual penal brasileira já prevê”. Isto porque:

Ora o Poder Legislativo estabeleceu exigências para o uso republicano e destinação dos fundos penitenciários a cargo da administração judicial e do Departamento Penitenciário Nacional. São, portanto, exigências legais, estabelecidas pelo Poder Legislativo. E não pelo Poder Judiciário. Além do mais o Fundo Penitenciário Nacional, gerido pelo Departamento Penitenciário Nacional, foi criado por Lei Complementar (LC 79/94 e regulamentada pelo Decreto 1093/94) (STRECK, 2015).

Apesar das críticas, Dirley da Cunha Junior (2016) argumenta que o Estado de Coisas Inconstitucional veio, na realidade brasileira, para fortalecer e resguardar as garantias dos direitos fundamentais, frente ao descaso dos órgãos estatais.

13 Tais informações podem ser extraídas do Site de Noticiais do Supremo Tribunal Federal (BRASIL, 2015b). 
Apesar das conhecidas críticas ao ativismo judicial, o reconhecimento do Estado de Coisas Inconstitucional pode reforçar o sistema de garantias dos Direitos Fundamentais, sobretudo de segmentos populacionais mais vulneráveis e afetados pelo estado de inércia e indiferença dos poderes públicos. Não vejo, entretanto, o ECI como um remédio milagroso a estimular ilusões. Mas pode servir pedagogicamente para (a) estimular a adoção de medidas reais e efetivas; (b) provocar um sério e sincero debate a respeito da falta ou insuficiência de políticas públicas em determinados setores sensíveis (não apenas no sistema penitenciário, mas também nos caóticos sistemas públicos de saúde, de ensino e de segurança pública); e (c) proporcionar a construção de soluções estruturais dialogadas e concertadas entre os poderes públicos, a sociedade e as comunidades atingidas (CUNHA JUNIOR, 2016).

Nessa mesma perspectiva, Carlos Alexandre Campos (2015) aduz que, devido à inércia parlamentar e administrativa, o ECI torna-se necessário, pois neste caso, o ativismo judicial evidenciar-se-ia como um meio, mesmo que seja esse distante do ideal democrático, para evitar a contínua violação dos direitos fundamentais e omissão dos poderes responsáveis.

$\mathrm{Na}$ verdade, o ECI prestar-se-ia a mobilizar os titulares de poder, de sorte que os "responsáveis assumam as rédeas de suas atribuições e adotem as medidas, dentro de sua esfera de competência, para solucionar o problema" (LIMA, 2015). Isto porque todas as medidas a serem tomadas devem respeitar a discricionariedade dos legisladores e administradores, considerando que, num primeiro momento, as autoridades são comunicadas do quadro geral. Posteriormente, os órgãos devem elaborar um plano de solução, com o estabelecimento de prazo para sua conclusão. Também compete aos poderes indicar órgãos de monitoramento e fiscalização para acompanhamento das medidas pelo Poder Judiciário.

A partir dessas posições, conclui-se que, apesar das divergências, o reconhecimento do Estado de Coisas Inconstitucional é visualizado como uma alternativa para minimizar a situação do sistema carcerário nacional, visto que foi através dessa decisão que o STF determinou a adoção de medidas administrativas e destinou os recursos orçamentários para tentar solucionar o problema da realidade penitenciária brasileira.

Porém, não há como negar que essa guinada jurisprudencial deve ser implementada com cautela, com claro estabelecimento de limites normativos, de forma a evitar a usurpação das competências dos demais Poderes pelo órgão Judiciário.

\section{CONCLUSÃO}

Com o Estado Democrático de Direito, o Judiciário passou a deter um imprescindível papel na tutela dos direitos fundamentais. A inconstitucionalidade rebatida pelo ECI é fruto de falhas estruturais na implementação de políticas públicas, na qual um grande número de pessoas tem seus direitos transgredidos, e para reverter esse quadro é necessário a intervenção de várias autoridades e poderes estatais. 
No Brasil, a tentativa de implantação do ECI se deu há pouco tempo, com o julgamento da ADPF $n^{\circ} 347 / \mathrm{DF}$, pugnando-se pelo reconhecimento do estado de barbárie em que se encontra o sistema carcerário brasileiro, no qual há violação massiva e generalizada dos direitos fundamentais dos presos. Nesse julgamento, é possível perceber a tentativa de balancear os direitos que devem ser resguardados aos presos e os princípios constitucionais democráticos. Porém, com a tentativa de reconhecimento do ECI no Brasil surgiram diversas críticas quanto à legitimidade e ao grau de interferência do Poder Judiciário na agenda de políticas públicas e no orçamento dos demais poderes.

Parte da doutrina defende que a decisão do STF viola a separação e a harmonia dos poderes, bem como a cláusula da reserva do possível. De outro lado, é sustentada a legitimidade do ativismo judicial, de caráter estrutural, como forma de proteger os direitos fundamentais diante da omissão legislativa e administrativa inconstitucional.

Com efeito, reconhece-se que o ativismo judicial, no seu aspecto institucional, implica numa disposição em anular atos dos demais poderes estatais ou estabelecer uma pauta de atuação, interferindo no exercício de atividades; contudo, somente merece rechaço quando em desconformidade com a garantia de direitos, no exercício do papel de guarda da Constituição (LIMA, 2014, p. 328).

Deste modo, os argumentos de respeito ao princípio da separação de poderes não se prestam a respaldar a omissão dos Poderes Executivo e Legislativo na concretização dos direitos fundamentais. Referido princípio, em sua concepção hodierna, não se restringe a uma perspectiva rígida e organicista, mas permanece como ideia racionalizadora do aparato estatal ou, ao menos, uma técnica de estruturação do poder para a garantia das liberdades (CLÈVE, 2000, p. 44). A funcionalização do poder hoje é dominada pelos critérios de eficácia, eficiência e legitimação na prossecução do interesse público. Assim, há uma conexão entre as características estruturais de cada órgão, suas funções e a auto-responsabilidade no seu desempenho, aptas a obter a melhor consecução das suas exigências. Segue-se um esquema racional de organização do trabalho, que garantiria uma estrutura funcionalmente adequada à realização das múltiplas tarefas do estado (NOVAIS, 1997, p. 38).

Neste sentido, o ativismo judicial estrutural, presente na declaração do Estado de Coisas Inconstitucional, pode ser considerado legítimo se, além de observados os seus rigorosos pressupostos, permitir ou catalisar o diálogo entre poderes e destes com a sociedade. Assim, o ECI é visualizado como um instrumento capaz de minimizar a paralisia parlamentar e administrativa sobre determinadas matérias. Na Colômbia, a experiência mostrou-se positiva, justamente pelo emprego destas cautelas, sob a noção de que as expectativas em torno de uma interpretação adequada do princípio da separação de poderes hoje tendem a beneficiar a integração e colaboração entre os ramos de governo. Assim, a migração de um instituto jurídico cujos contornos foram estabelecidos num país vizinho, que enfrenta desafios de efetivação de direitos similares aos brasileiros, mostra as vantagens do engajamento em um profícuo diálogo entre cortes na América do Sul. 


\section{REFERÊNCIAS}

ARIZA, Libardo José. The economic and social rights of prisoners and constitutional court intervention in the penitentiary system in Colombia. In: MALDONADO, Daniel Bonilla. Constitutionalism of the Global South: the activist tribunals of India, South Africa and Colombia. New York: Cambridge University Press, 2013. p. 129-159.

BALDI, Cesar. Del constitucionalismo moderno al nuevo constitucionalismo latinoamericano descolonizador. Revista de Derechos Humanos y Estudios Sociales, Sevilla, v. 5, n. 9, p. 51 72, enero/jun. 2013.

BARROSO, Luís Roberto. Contramajoritário, representativo e iluminista: os papéis das Cortes Constitucionais nas democracias contemporâneas. In: BARROSO, Luís Roberto. Jurisdição Constitucional e Debates Públicos. Brasília, 2015. Disponível em: http://www.luisrobertobarroso.com.br/wp-content/uploads/2015/12/O-papel-das-cortes-constitucionais.pdf. Acesso em: 10 nov. 2017.

BAUM, Lawrence. The Supreme Court. Ohio: CQ Press, 2010.

BRASIL. Lei $\mathbf{n}^{\circ}$ 9.882, de 3 de dezembro de 1999. Dispõe sobre o processo e julgamento da argüição de descumprimento de preceito fundamental, nos termos do $\S 1$ o do art. 102 da Constituição Federal. Brasília: Presidência da República, 1999. Disponível em: http://www. planalto.gov.br/ccivil_03/leis/19882.htm. Acesso em: 5 jun. 2016.

BRASIL. Supremo Tribunal Federal. Medida Cautelar na Argüição de Descumprimento de Preceito Fundamental 347 Distrito Federal. Relator: Min. Marco Aurélio, 9 de setembro de 2015a. Disponível em: http://redir.stf.jus.br/paginadorpub/paginador.jsp?docTP=TP\&do$\mathrm{cID}=10300665$. Acesso em: 15 nov. 2015.

BRASIL. Supremo Tribunal Federal. Notícias STF. In: BRASIL. Supremo Tribunal Federal. Portal do Supremo Tribunal Federal. Brasília, 27 ago. 2015b. Disponível em: http://www.stf. jus.br/portal/cms/verNoticiaDetalhe.asp?idConteudo=298600\&caixaBusca=N. Acesso em: 20 out. 2017.

BRASIL. Supremo Tribunal Federal. Recurso Extraordinário 592.581/RS. Relator: Min. Ricardo Lewandowski, 13 de agosto de 2015c. Disponível em: http://www.stf.jus.br/arquivo/cms/ noticiaNoticiaStf/anexo/592581.pdf. Acesso em: 20 dez. 2015.

CAMPOS, Carlos Alexandre de Azevedo. Estado de Coisas Inconstitucional. Salvador: JusPodivm, 2016.

CAMPOS, Carlos Alexandre de Azevedo. O Estado de Coisas Inconstitucional e o litígio estrutural. Consultor Jurídico, [S. l.], 1 set. 2015. Disponível em: http://www.conjur.com.br/ 2015-set-01/carlos-campos-estado-coisas-inconstitucional-litigio-estrutural. Acesso em: 14 abr. 2017.

CARVALHO, Gustavo Ferreira de; OLIVEIRA, Fábio de Souza; SANTOS, Júlio Edstron S. O Estado de Coisas Inconstitucional: é possível sua efetivação no Brasil? Revista Acadêmica Conecta FASF, Luz, v. 1, n. 2, p. 307-332, 2017. 
CLÈVE, Clemerson Merlin. A atividade legislativa do Poder Executivo. São Paulo: Revista dos Tribunais, 2000.

CNJ - CONSELHO NACIONAL DE JUSTIÇA. CNJ divulga dados sobre nova população carcerária brasileira. In: CNJ. Portal do CNJ. Brasília, 2014. Disponível em: http://www.cnj.jus.br/ noticias/cnj/28746-cnj-divulga-dados-sobre-nova-população-carceraria-brasileira. Acesso em: 18 ago. 2017.

COLÔMBIA. Corte Constitucional. Sentencia SU-559/97. Bogotá: Corte Constitucional de Colombia, 1997. Disponível em: http://www.corteconstitucional.gov.co/relatoria/1997/SU559-97. htm. Acesso em: 2 abr. 2017.

COLÔMBIA. Corte Constitucional. Sentencia T-025/04. Bogotá: Corte Constitucional de Colombia, 2004. Disponível em: http://www.corteconstitucional.gov.co/relatoria/2004/T-025-04. htm. Acesso em: 2 abr. 2017.

COLÔMBIA. Corte Constitucional. Sentencia T-153/98. Bogotá: Corte Constitucional de Colombia, 1998. Disponível em: http://www.corteconstitucional.gov.co/relatoria/1998/T-153-98. htm. Acesso em: 2 abr. 2017.

CUNHA JUNIOR, Dirley da. Estado de Coisas Inconstitucional como garantia de direitos fundamentais. In: JUS. [S. l.], mar. 2016. Disponível em: https://jus.com.br/artigos/47193/o-estado-de-coisas-inconstitucional-como-garantia-de-direitos-fundamentais. Acesso em: 16 out. 2017.

CUNHA JUNIOR, Dirley da. Estado de Coisas Inconstitucional. In: BRASIL JURÍDICO. Ensino de Alta Performance. Salvador, 10 dez. 2015. Disponível em: https://www.brasiljuridico. com.br/artigos/estado-de-coisas-inconstitucional. Acesso em: 24 jul. 2017.

DE GIORGI, Raffaele; FARIA, José Eduardo; CAMPILONGO, Celso. Estado de Coisas Inconstitucional. O Estado de S. Paulo, São Paulo, 19 set. 2015. Disponível em: http://opiniao.estadao. com.br/noticias/geral,estado-de-coisas-inconstitucional,10000000043. Acesso em: 16 out. 2017.

GARAVITO, César Rodríguez; FRANCO, Diana Rodríguez. El contexto: el desplazamiento forzado y la intervención de la Corte Constitucional. In: GARAVITO, César Rodríguez; FRANCO, Diana Rodríguez. Cortes y cambio social: cómo la Corte Constitucional transformó el desplazamiento forzado en Colombia. Bogotá: De Justicia, 2010.

HERNÁNDEZ, Clara Inés Vargas. La Garantía de la dimensión objetiva de los derechos fundamentales y labor del juez constitucional colombiano em sede de acción de tutela: el llamado "estado de cosas inconstitucional". Revista del Centro de Estudios Constitucionales, Talca, v. 1, n. 1, p. 203-228, 2003.

HIRSCHL, Ran. Towards juristocracy: the origins and consequences of the constitutionalism. Cambridge: Harvard University Press, 2004.

LIMA, Flávia Danielle Santiago. Jurisdição constitucional e política: ativismo e autocontenção no STF. Curitiba: Juruá, 2014.

LIMA, George Marmelstein. O Estado de Coisas Inconstitucional - ECI: apenas uma nova onda do verão constitucional? In: LIMA, George Marmelstein. Direitos Fundamentais.net. [S. l.], 2 out. 2015. Disponível em: http://direitosfundamentais.net/2015/10/02/o-estado-de-coisas-incons- 
titucional-eci-apenas-uma-nova-onda-do-verao-constitucional/. Acesso em: 30 out. 2017.

LOSING, Norbert. La jurisdiccionalidad constitucional em Latinoamérica. Madrid: Dykson, 2002.

MONTENEGRO, Germán Santiago. Las incidencias del Estado de Cosas Inconstitucional en la jurisprudencia colombiana: el desplazamiento de los resguardos nulpe medio y gran sábalo de la comunidad indígena Awá. 2015. Trabalho de Conclusão de Curso (Graduação em Direito) Universidad Católica de Colombia, Bogotá, 2015.

NEVES, Marcelo. Do diálogo entre as cortes supremas e a Corte Interamericana de Direitos Humanos ao transconstitucionalismo na América Latina. Revista de Informação Legislativa, Brasília, v. 51, n. 201, p. 193-214, jan./mar. 2014.

NOVAIS, Jorge Reis. Separação de poderes e limites da competência legislativa da Assembléia da República: simultaneamente um comentário ao Acórdão no 1/97 do Tribunal Constitucional. Lisboa: Lex, 1997.

PEREIRA, Jane Reis Gonçalves; GONÇALVES, Gabriel Accioly. Inconstitucionalidade sistêmica e multidimensional: transformações no diagnóstico das violações à Constituição. Juris Poiesis, Rio de Janeiro, v. 18, n. 18, p. 130-159, jan./dez. 2015.

QUINTERO LYONS, Josefina; NAVARRO MONTERROZA, Angélica Matilde; IRINA MEZA, Malka. La figura del Estado de Cosas Inconstitucionales como mecanismo de protección de los derechos fundamentales de la población vulnerable en Colombia. Revista Jurídica Mario Alario D'Filippo, Cartagena, v. 3, n. 1, p. 69-80, 2011.

SILVA, Virgílio Afonso da. Integração e diálogo constitucional na América do Sul. In: BOGDANDY, Armin von; PIOVESAN, Flávia; ANTONIAZZI, Mariela Morales (org.). Direitos humanos, democracia e integração jurídica na América do Sul. Rio de Janeiro: Lumen Juris, 2010. p. 515-530.

SLAUGHTER, Anne-Marie. A global community of courts. Harvard International Law Journal, Cambridge, v. 44, p. 191-219, 2003.

STRECK, Lenio Luiz. Estado de Coisas Inconstitucional é uma nova forma de ativismo. Consultor Jurídico, [S. l.], 24 out. 2015. Disponível em: http://www.conjur.com.br/2015-out-24/observatorio-constitucional-estado-coisas-inconstitucional-forma-ativismo. Acesso em: 20 out. 2017.

VIEIRA, Oscar Vilhena. Supremocracia. Revista Direito GV, São Paulo, v. 4, n. 2, p. 441-464, jul./dez. 2008.

VIEIRA, Samuel de Jesus. O estado de coisa inconstitucional e a necessidade brasileira de se adotar o ativismo dialógico e a ordem de desbloqueio nas atividades da administração pública. Âmbito Jurídico, São Paulo, v. 19, n. 149, jun. 2016. Disponível em: http://www.ambito-juridico.com.br/site/index.php?n_link=revista_artigos_leitura\&artigo_id $=17354 \&$ revista_caderno $=9$. Acesso em: 18 jul. 2017.

VILLALOBOS, Carlos José Lasprilla; MACHADO, Daniela Sanclemente. El Estado de Cosas Inconstitucional como la maxima expresion del activismo del juez de tutela. In: VILLALOBOS, Carlos José Lasprilla; MACHADO, Daniela Sanclemente. El juez de tutela como arquitecto 
del Estado Social de Derecho. Bogotá: Grupo Editorial Ibañez, 2014.

WALDRON, Jeremy. Foreign law and the modern Ius Gentium. Harvard Law Review, Cambridge, v. 129, p. 119-135, 2005.

YEPES, Rodrigo Uprimny. Judicialization of politics in Colombia: cases, merits and risks. Sur: Revista Internacional de Direitos Humanos, São Paulo, v. 4, n. 6, p. 52-69, 2007.

Como citar: LIMA, Flávia Danielle Santiago; CLEMENTINO, Gabriella Caldas. Diálogos entre cortes: o estado de coisas inconstitucional na Colômbia e no Brasil (ADPF 347/DF). Revista do Direito Público, Londrina, v. 15, n. 1, p. 153-173, abr. 2020. DOI: 10.5433/24157-108104-1.2020v1 5n1p. 153. ISSN: 1980-511X

Recebido em: 23/01/2019

Aprovado em: 24/06/2019 